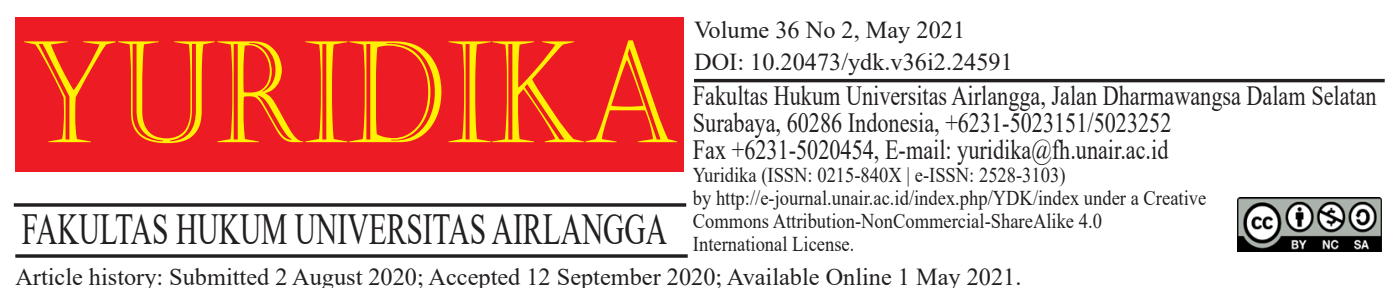

\title{
Medical Malpractice in the United States of America: Lessons to Learn for Indonesia
}

\author{
Muh Endriyo Susila \\ endriosusilo@umy.ac.id \\ Universitas Muhammadiyah Yogyakarta
}

\begin{abstract}
Many countries have established a system that serves the liability and settlement of medical malpractice disputes in response to rising medical malpractice claims against doctors. The medical malpractice system in the United States of America (USA) is relatively well developed compared to other countries. Besides the pretrial screening process in medical malpractice litigation, various alternatives to litigation have been developed in the USA. This paper aims to explore the development of the medical malpractice system in the USA and the lessons Indonesia can learn from it. This normative legal research relies on secondary data, particularly online sources. It found that Indonesia can adopt some initiatives in the USA to improve its medical malpractice system, especially the pretrial screening panel. The pretrial screening process is expected to eliminate frivolous claims and reduce unnecessary legal actions against doctors.
\end{abstract}

Keywords: Medical Malpractice; Medical Malpractice System; the USA; Indonesia.

\section{Introduction}

The growth of medical malpractice cases is a global phenomenon, ${ }^{1}$ and countries are seeking ways to encourage amicable settlements. Alternative dispute resolution (ADR) is one solution that has attained acceptance worldwide. Following the successful implementation of ADR in other countries, ADR methods, especially mediation, have been adopted in Indonesia to resolve medical malpractice disputes. ${ }^{2}$

${ }^{1}$ OALAdmin, 'How Is Medical Malpractice Different in the USA?' (Nelson, MacNeil, Rayfield Trial Attorneys PC, 13 November 2017) <www.nelsonmacneil.com/blog/how-medicalmalpractice-different-us $/>$.

${ }^{2}$ Section 29 of the Health Act 2009 provides that mediation is mandatory for all disputes involving health-care professionals. 
In Indonesia, ADR is still in its infancy, and more efforts are needed to improve it. Since 2009, ADR, especially mediation, has been made mandatory in settling medical malpractice disputes, but its application encounters various obstacles, including regulatory. Therefore, it is useful to look at the best practices in different jurisdictions, especially the USA, which has successfully developed various medical malpractice dispute settlement methods outside the court system.

\section{Medical Malpractice in the USA}

The USA is characterised as a litigious society. The litigation process in courts is more intense in the USA compared to other jurisdictions. Moreover, the litigious nature of American society has seriously affected the medical profession. Medical malpractice lawsuits are a relatively common occurrence in the USA. ${ }^{3}$

The increase in medical malpractice litigation has caused the USA to suffer from a medical malpractice crisis. Since the 1970s, the USA has experienced three medical malpractice crisis periods characterised by significant increases in the premiums and contractions in the supply of malpractice insurance. ${ }^{4}$ These increases have been attributed to various factors, but doctors claim that a prime source is 'unfounded' or frivolous lawsuits. ${ }^{5}$

Since the early 1970s, legislatures and courts have struggled to reform the law governing medical malpractice claims. Many proposed reforms promote economic efficiency through some specific cost-containment or damage-limitation mechanism. Other proposals seek to deter the filing of 'frivolous' claims. Most proposals give

\footnotetext{
${ }^{3}$ B Sonny Bal, 'An Introduction to Medical Malpractice in the United States' (2009) 467 Clinical Orthopaedics and Related Research.[339].

${ }^{4}$ Ben CJ van Velthoven and Peter W van Wijck, 'Medical Liability: Do Doctors Care?' (2012) 33 (2) Recht der Werkelijkheid.[28-29].

${ }_{5}^{5}$ The medical community has resorted to a multifaceted counterattack to try to curb this perceived medical malpractice crisis. Medical associations have sponsored legislation that penalises the plaintiffs of frivolous suits and have organised countersuit funds for doctors who become the victims of such litigation. Moreover, a non-profit organisation was formed to develop public awareness and solutions for the problems of frivolous malpractice suits. Mary Jane Yardley, 'Malicious Prosecution: A Doctor's Need for Reassessment' (1984) 60 Chicago Kent Law Review.
} 
no attention to the law's role in protecting the dignity of the participants. Economic considerations command the reformers' exclusive attention. ${ }^{6}$

Various solutions have been proposed to reform the tort system and thereby reduce the rippling effects of the malpractice crisis on the cost and delivery of health care. The impetus for tort reforms comes from the heavy costs of litigation to the American health-care system. According to several reliable statistics, the numbers are staggering: $10 \%$ of all annual expenditures for health care in the USA goes to medical liability and defensive medicine; USD 32.6 billion is spent annually on professional liability claims and expenses for hospitals, long-term care facilities and doctor's malpractice awards; and the total annual allocation to the legal industry is USD 246 billion per year. ${ }^{7}$

Medical malpractice litigation costs are growing 7.5\% annually. Hookman estimates that $50-80 \%$ of payouts by self-insured hospitals, long-term care facilities and medical malpractice insurance companies go directly to attorney's fees (defence and plaintiff) and 'administrative costs' and 25\% goes to adjusted loss allocation expenses. Of the amount awarded to the injured patient (plaintiff), 35-50\% goes to the plaintiff's attorney as a contingency fee award. Moreover, tort reform in several states may keep some cases from entering the pipeline. For any case that does enter the pipeline, more than $50 \%$ goes to attorney fees (defence and plaintiff) ${ }^{8}$

In response to the malpractice crisis, a majority of American states have adopted tort reform measures aiming to reduce the overall costs of medical liability. The extent and specifics of tort reform vary from state to state. Some reforms make it more costly or difficult to file tort cases, while others aim to reduce damage awards. The following list gives an overview of the most commonly adopted tort reforms: ${ }^{9}$

\footnotetext{
${ }^{6}$ Frank M McClellan, Medical Malpractice (Temple U Press 1994) ix.

${ }^{7}$ The statistics refer to the 2006AHAHospital Statistics, 2004 on Hospital Professional Liability and Doctor Benchmark Analysis, 2004's Aggregates \& Averages, and PricewaterhouseCoopers 2006. Perry Hookman, Medical Malpractice Expert Witnessing: Introductory Guide for Doctor and Medical Professionals (CRC Press 2008).[203].

${ }^{8}$ ibid.

${ }^{9}$ van Velthoven and van Wijck (n 4).[39-40].
} 
1) Shorter statutes of limitation: limit the amount of time a patient has to file a malpractice claim after the occurrence or discovery of the injury.

2) Contingency fee reform: limits the amount of a damage award that a plaintiff's attorney may take in a contingent fee arrangement.

3) Pretrial screening panels: review a malpractice case at an early stage and assess whether a claim has sufficient merit to proceed to trial.

4) Caps on damages: limit the amount of money that a plaintiff can take as an award. The cap may apply to non-economic damages (pain and suffering), total damages, or only punitive damages.

5) Joint-and-several liability reform: limits the financial liability of each individual, in cases involving more than one defendant, to the percentage fault of the individual.

6) Collateral source rule reform: eliminates the traditional rule that any compensation a plaintiff receives from other sources, such as health insurance, should not be deducted from the damage award.

7) Periodic payment: allows or requires insurers to pay out malpractice awards over a longer period of time, rather than in a lump sum.

Besides gaining popularity from the malpractice crisis phenomenon, the USA has been frequently referred to as having patient safety issues. ${ }^{10}$ Medical error has been alleged as a more dangerous killer than traffic accidents. ${ }^{11}$ Medical malpractice litigation is a common phenomenon that has created social and economic problems in the USA. ${ }^{12}$ However, the litigation system for malpractice cases contains several deficiencies that encourage the American government to continue tort reform. ${ }^{13}$

${ }^{10}$ The issue of patient safety arose in response to the large number of incidents in hospitals due to human error. Such incidents (commonly referred to as adverse events) are preventable, especially when hospital staff exercise due care in providing health-care service. Patient safety became a global movement, especially after the release of the Institute of Medicine's report in 1999.

${ }^{11}$ Based on the landmark report of the Institute of Medicine (IOM) 1999, medical error is responsible for the death of at least 44,000 patients in hospital every year.

${ }^{12}$ The direct costs of the malpractice liability system are widely estimated to be USD 20-30 billion per year, while the indirect costs (principally defensive medicine) are USD 100-300 billion per year. David A Hayman and Charles Silver, 'Medical Malpractice and Global Perspective: How Does the USA Do It' (2012) 87 Chicago Kent Law Review.

${ }^{13}$ Peter P Budetti and Teresa M Waters explained that the traditional reliance on state courts to shape medical malpractice law started to change in the last three decades of the 20th century. As premiums for malpractice insurance climbed sharply, organised medicine began to pressure state legislatures to change the rules governing malpractice lawsuits created by judges over the previous two centuries. State legislatures have responded to a number of issues concerning the malpractice tort claims system and passed statutes that changed different aspects of malpractice law, some of which had dramatic effects. Those statutes are often referred to as 'tort reforms'. More recently, the United States Congress has also considered legislation that would make federal laws more prominent in medical malpractice cases and would override at least some aspects of state laws. Peter P Budetti and Tereza M Winters, 'Medical Malpractice Law in United States' (The Henry J Kaiser Family Foundation 2005). 
While traditional malpractice reform efforts could reduce the number and success of malpractice lawsuits in some states, they do little to help patients injured by doctor negligence obtain what research suggests they truly desire: (1) an account of why the harm occurred; (2) an apology from the health-care professionals involved; (3) information about how similar harms can be avoided in the future; and (4) appropriate restitution for an avoidable harm. ${ }^{14}$

A 2013 study estimated that $210,000-400,000$ people die annually in the USA due to medical errors. Ethically, a reformed medical malpractice system must address the fact that medical errors do injure patients and are at play in a significant number of malpractice cases. For example, Studdert and others analysed 1,452 closed malpractice claims from five liability insurers and concluded that $63 \%$ of the claims did involve injuries due to medical error. ${ }^{15}$

\section{Medical Malpractice System in the USA}

Medical malpractice law in the USA derived from English common law and was developed by rulings in various state courts. The legal system encourages extensive discovery and negotiations between adversarial parties to resolve disputes without a jury trial. The injured patient must show that the doctor acted negligently in rendering care and that such negligence resulted in injury. To do so, four legal elements must be proven: (1) a professional duty owed to the patient; (2) breach of such duty; (3) injury caused by the breach; and (4) resulting damage. Many damages, if awarded, typically take into account actual economic loss and noneconomic loss, such as pain and suffering. ${ }^{16}$

\footnotetext{
${ }^{14}$ Joseph S Kass and Rachel V Rose, 'Medical Malpractice Reform: Historical Approaches, Alternative Models, and Communication and Resolution Programs' (2016) 18 American Medical Association Journal of Ethics.

${ }^{15}$ ibid. [303].

${ }^{16} \mathrm{Bal}$ (n 3) 339. For further discussion pertaining to the nature of the US legal system, see United States Department of State, Bureau of International Information Programs, 'Outline of the USA Legal System' (2004). 'Where no statute or constitutional provision controls, both federal and state courts often look to the common law, a collection of judicial decisions, customs, and general principles that began centuries ago in England and continues to develop today' ibid 12. See also Stephen W Heath, Risk Management and Medical Liability (Indian Health Service 2006).
} 
Medical malpractice law in the USA traditionally has been under the authority of the states, not the federal government. Unlike many other areas of law, the framework and legal rules governing malpractice actions were, prior to the last 30 years, largely established through case law (court decisions) rather than state statutes. The case law in one state has no weight in another state, so the rules for handling medical malpractice cases vary from state to state, although many of the principles are similar. ${ }^{17}$

Dissatisfied patients in the USA have two primary means of complaining. They can contact the relevant state licensing board, which may revoke or limit the licences of doctors found to have acted improperly, or sue the doctors when they can find lawyers willing to represent them. The utility of the first mechanism varies greatly from state to state. Some states are more likely to initiate disciplinary proceedings against individual doctors than others. Generally speaking, only the most egregious cases seem likely to interest state medical boards. For the second mechanism, it is almost impossible to secure a recovery without help from a plaintiff's lawyer when liability is contested. According to Hayman, obtaining counsel is harder than one might think. Plaintiff's lawyers work on contingency; they screen cases carefully and decline most requests for representation. ${ }^{18}$

The tort litigation system has been criticised for being inefficient, unfair and costly to patients, health-care providers and the health-care system. To overcome the problems associated with the tort litigation system, several methods have been suggested as an alternative to the existing tort litigation system in the USA. ${ }^{19}$

\footnotetext{
${ }^{17}$ Medical malpractice law in the United States traces its roots back to 19th-century English common law. The law that developed concerning medical malpractice is part of the more general body of law dealing with injuries to people or property, known as 'tort law'. Medical malpractice cases are an example of one particular type of tort, known as 'negligence'. The concept of negligence is that people should be reasonably careful in what they do, and, if they are not, they should be held responsible for the injuries that can be reasonably foreseen as resulting from their negligent conduct. See Budetti and Winters (n 13).[2].

${ }^{18}$ One study found that a plaintiff's law firm declined 29 of 30 requests for representation, a $97 \%$ rejection rate, and also paid independent doctor-experts to review the cases it took. Once cases are accepted, plaintiffs' lawyers research claims extensively using a compulsory process, and they frequently drop cases when new information creates doubt about the merits. See David A. Hayman and Charles Silver (n 12).[171].

${ }^{19}$ World Bank, 'Medical Malpractice Systems around the Globe: Examples from the USATort Liability System and the Sweden- No Fault System' (2003).
} 


\section{Alternatives to Litigation in Medical Malpractice Disputes in the USA}

\section{Alternative Dispute Resolution}

American courts have encouraged parties in medical malpractice disputes to use ADR to produce cheaper and faster settlements. ${ }^{20}$ Some states run very successful ADR programmes as an alternative to medical malpractice litigation, including Wisconsin. Colorado and other states are trying to get into this position to decrease the load on the courts. ${ }^{21}$

ADR models allow doctors and the health-care systems in which they operate to acknowledge openly when errors have occurred and offer reasonable compensation to the injured parties. They also balance the needs of clinicians to act ethically by being truthful and engaging in vigorous quality improvement and patients to receive compensation for negligence-induced iatrogenic injury. ADR allows litigants to move out of a 'battle' mentality and into a facilitated conversation to achieve resolution of the conflict. ${ }^{22}$ Discussion on the use of ADR to resolve medical malpractice disputes is limited to three ADR methods: arbitration, mediation, and communication and resolution programme (CRP).

a. Arbitration

Arbitration is the referral of a dispute for determination by a third party (the arbitrator) whose decision is based on the facts of the case and the evidence submitted by the parties. The parties agree to abide by the decision, known often as the award. The presentation of evidence, however, is informal. Because arbitration is a private procedure, the parties do not run the risk of any damaging publicity, which can arise out of reports of court proceedings. Arbitration proceedings are less formal than court proceedings. There are no technical rules of evidence and procedures used by the courts. They generally cost less and are less time-consuming. Parties have the

\footnotetext{
${ }^{20}$ John Farrar, Legal Reasoning (Thomson Reuters 2010) 85. See also Ralph Williams, Should the State Provide ADR Services (CJQ 1987).[142].

${ }^{21}$ Hookman (n 7).[201].

${ }^{22}$ Kass and Rose (n 14).[303].
} 
power to decide the time and place to conduct the proceedings. ${ }^{23}$

In the USA, arbitration has been applied in medical malpractice cases for more than 20 years, making it the oldest and most common form of the three alternative processes. Arbitration in medical dispute cases is mandated by statute in Michigan and California. ${ }^{24}$ However, arbitration has been criticised for becoming a legalised and operating institution of the law. Arbitration falls short of some of its potential ideas, such as flexibility, informality and efficiency. ${ }^{25}$ Moreover, arbitration shares similar characteristics with litigation, such as handing awards to plaintiffs if the arbitrator finds that the plaintiff has proved his case, following prescribed procedures that make it formal and permitting the parties to agree to apply the rules of evidence. ${ }^{26}$

b. Mediation

Mediation was once part of the dispute resolution landscape in the USA but not widespread. However, during the 1960s and the 1970s, the development of the trial process and a 'litigation explosion' led courts and legislators to begin mediation programmes in domestic relations cases and small claims cases. Thus, mediation grew from a small practice to several civil areas and even criminal areas. ${ }^{27}$

Mediation is the process by which the participants, with the assistance of a neutral person(s), systematically isolate disputed issues to develop options, consider alternatives and reach a consensual settlement that will accommodate their needs. ${ }^{28}$ There is a diversity of mediation practices. Boulle and Nesic examined the four distinguished models of mediation: facilitative, evaluative, settlement, and

${ }^{23}$ Laurenca Boulle and Kathleen J Kelly, Mediation: Principles, Process, and Practice (Butterworths 1998).[78].

${ }^{24}$ John J Fraser, Jr, 'Technical Report: Alternative Dispute Resolution in Medical Malpractice' (2001) 107 Pediatrics 604. See also Hookman (n 7).[205].

${ }^{25}$ Arbitration has a close interaction with the court system because the parties can obtain court orders to assist the arbitration and secure the court involvement in enforcing the arbitral awards. See Boulle and Kelly (n 23).[78].

${ }^{26}$ David Spencer and Tom Altobelli, Dispute Resolution in Australia: Cases, Commentary and Materials (Lawbook Co 2005).[227].

${ }^{27}$ David Spencer and Michael Brogan, Mediation Law and Practice (CUP 2006).[25-27].

${ }^{28}$ Jay Folberg and Alison Taylor, Mediation: A Comprehensive Guide to Resolving Conflict without Litigation (Jossey-Bass Publishers 1984).[7]. 
transformative (also referred to as therapeutic). ${ }^{29}$

The facilitative model, sometimes referred to as 'pure mediation' or the 'classic mediation process', is the oldest. The mediator plays a neutral role in aiding the parties to reach a solution that is agreeable to both. The mediator helps them analyse the issues and explore favourable options and offers advice and opinions regarding the outcome. It is a referee role in controlling an otherwise hostile situation. ${ }^{30}$

Evaluative mediation is a hybrid form of mediation and arbitration. The mediator performs a quasi-arbitral function by identifying the weakness of the arguments of both parties and even making predictions of the reactions of a judge or jury. The main difference between both types is that the latter is more focused on the legal aspect of the parties than on the personal interests and needs. ${ }^{31}$

Settlement mediation occurs in court or other institutional settings that control and limit the processes used and the possible outcomes. In such mediation, the setting is the key to how mediation can be conducted and with greater rigidity. Transformative mediation, also referred to as therapeutic mediation, seeks to change either the dispute or disputants, such as by altering their appraisal of each other and their place in the world or using professional therapeutic techniques. A decision is not reached until the relationship between the disputants has been addressed. ${ }^{32}$

Mediation has been effective in medical malpractice cases where the parties want to preserve their relationship or lack of communication has led to the dispute. ${ }^{33}$ As Yee observes, mediation helps preserve the doctor-patient relationship of the parties. The possibility of such a relationship surviving has a slim chance in litigation. When medical negligence occurs, patients usually want three things:

\footnotetext{
${ }^{29}$ Laurence Boulle and Miryana Nesic, Mediation: Principles, Process, and Practice (Butterworths 2001).[27-29].

${ }^{30}$ ibid.

${ }^{31}$ ibid.

${ }^{32}$ ibid.

${ }^{33}$ Fraser (n 24).[603].
} 
the error's cause, an apology from the doctor or hospital, and assurance that the mistake will not happen again. It may also deter future negligence on the part of the doctors. ${ }^{34}$

Fraser mentions that the advantages of mediation are lower costs, confidential proceedings, and the degree of control the disputing parties enjoy over the process and the outcomes. Mediation can be favourable for injured parties because they can express their concerns and may lead to an acknowledgement of the problem, sometimes in the form of an apology. ${ }^{35}$ Yee suggests that mediation can avoid the soaring costs associated with litigation, such as lawyer fees and other expenses. Furthermore, whereas the transactional costs of processing the dispute through the legal system exceed the amount awarded, parties benefit more from mediation because it is less costly. ${ }^{36}$

Several states have mandated mediation in medical malpractice cases, Connecticut being the most recent. As of 1 July 2010, judges in Connecticut must refer medical malpractice cases to a 120 -day mediation period or other ADR process before the close of proceedings. ${ }^{37}$

Wisconsin has a Mandatory Mediation Panel System (MMPS) that consists of a lawyer who chairs the panel, a doctor or other health-care professional with experience on the subject matter of the claim and a member of the public. Claimants can file claims for medical negligence 15 days before commencing the proceedings, and mediations must be completed within 90 days. The panel aims to facilitate the settlement by identifying the strengths and weaknesses in each party's position and discussing alternative options. The panel makes no binding recommendations or decisions. ${ }^{38}$ Several medical universities have also adopted formal medical malpractice programmes, such as Drexel University's College

\footnotetext{
${ }^{34}$ Florence Yee, 'Mandatory Mediation: The Extra Dose Needed to Cure the Medical Malpractice Crisis' (2006) 7 Cardozo Journal of Conflict Resolution.

${ }^{35}$ Fraser (n 24).[603-604].

${ }^{36}$ Yee (n 34).[418].

37 'Connecticut Mandates Mediation for Medical Malpractice Cases'.

${ }^{38}$ Boulle and Nesic (n 29).[296].
} 
of Medicine, the University of Pittsburgh Medical Center and the University of Michigan Health System (UMHS). ${ }^{39}$

Federal legislation was introduced in the House of Representatives to encourage mediation, reduce litigation costs and fund mediation programmes addressing medical malpractice claims. The Comprehensive Medical Malpractice Reform Act of 2005 sought to fund mediation programmes through grants administered by the Department of Justice. ${ }^{40}$

Liebman and Hyman highlight the ability of mediation, especially facilitative, to address fundamental issues underlying medical malpractice claims, including the need for communication. Surveys show there are several reasons people file medical malpractice cases. One reason pertains to the inability of doctors and hospitals to communicate with the victim or the victim's family over the error or negligence for fear of their words being used in court. On the other hand, claimants resort to litigation when they need answers. Money is not all that the claimants desire; it could be answers or an apology. Therefore, compensation or awards may not be the most satisfactory outcome for either party because communication is an important aspect of the medical relationship between the health-care practitioner and patient. ${ }^{41}$

Liebman explains that in the past decade, the American health-care system has begun to use mediation to facilitate communication between patients and doctors after an adverse medical event, ease tensions among members of caregiving teams, resolve medical malpractice claims, and help family members and medical professionals make decisions at the end of life. Implementation of the Patient Protection and Affordable Care Act of 2010 will produce new controversies and

\footnotetext{
${ }^{39}$ Lee A Rosengard and Marissa Parker, 'Committing to Mediation: Enriched Resolution of Medical Malpractice Actions for Patients, Doctors and Insurance Companies’ (2009).

${ }^{40}$ Nafiza Ali, 'Facilitative Mediation in Resolving Medical Negligence Disputes' (4th APMF Conference, Kuala Lumpur, Malaysia, 16-18 June 2008).

${ }^{41}$ Such a communication can generally be achieved via mediation, especially facilitative mediation with the mediator's role kept to a minimum. Arbitration and evaluative mediation bear too much resemblance to the litigation process whereas facilitative mediation is different in nature. See Carol B Liebman and Chris Stern Hyman, 'Disclosure and Fair Resolution of Adverse Events' in William M Sage and Roger Kersh (eds), Medical Malpractice and the USA Health Care System (CUP 2006).[191-216].
} 
increase the need for mediation. Patients, families, doctors, nurses, other health-care professionals, and administrators will require help managing the disagreements that arise as they adapt to the altered health-care system. ${ }^{42}$

c. Communication and Resolution Programme

ADR, especially mediation and arbitration, can be quite effective in resolving disputes in a less adversarial and less costly manner than traditional litigation. Several health-care institutions have experimented with a unique twist by developing CRPs, novel approaches to addressing medical error that have paid off in terms of the costs associated with malpractice litigation. These programmes encourage open communication and transparency with patients and their families and facilitate restitution for injured parties when appropriate. They also support doctors in disclosure conversations with patients. ${ }^{43}$

The Lexington Veterans Affairs (VA) Medical Center is a pioneer in this area. In 1987, the Lexington VA implemented its CRP, providing full disclosure of the occurrence that led to the harm and an expression of regret on behalf of the institution and its personnel. Under this system, patients and their families are invited to bring attorneys to discuss compensation offers early in the process. ${ }^{44}$

CRPs also exist outside the VA system and come in two varieties: early settlement and limited reimbursement. UMHS was the first non- VA health system to adopt a CRP, implementing an early settlement model in 2001. UMHS selfinsures; all its doctors are employed and insured by the university rather than commercial malpractice carriers, thereby simplifying buy-in to the CRP. This model has four components: (1) acknowledging when patients are injured due to medical

${ }^{42}$ Carol B Liebman, 'Medical Malpractice Mediation, Benefits Gained, Opportunities Lost' (2011) 74 Law and Contemporary Problem.[135].

${ }^{43}$ Kass and Rose (n 14).[303].

${ }^{44}$ Although ADR in a health care situation likely benefits both the health care provider (by promoting honesty and ethical behaviour) and the patient and patient's family (by providing an honest accounting of what happened, including a statement of regret and possibly an offer of compensation), the empirical literature on ADR typically emphasises payouts as a measure of success. With the implementation of this programme, the Lexington VA became the VA hospital with the lowest payouts. Between 1990 and 1996, the average settlement per claim in Lexington was approximately USD 15,622, whereas in other VA institutions it was USD 98,000. Additionally, the average duration of cases decreased from 2-4 years to 2-4 months. See ibid. 
error; (2) compensating fairly (commensurate with the degree of harm) and quickly when there is a deviation from the standard of care; (3) aggressively defending against frivolous cases; and (4) studying all adverse events to determine how health-care delivery can be improved. Because the payments are made on behalf of the institution only, they are not reported to the National Practitioner Data Bank (NPDB). This operational detail is significant. The NPDB was created by Congress and 'contains information on medical malpractice payments and certain adverse actions related to health-care practitioners, entities, providers, and suppliers'. This publicly available information may affect a doctor's reputation and follows a doctor throughout their career. ${ }^{45}$

\section{No-Fault Compensation Scheme}

After discussing ADR methods, it is also important to examine the no-fault liability scheme, which the USA has not adopted. Hyman and Silver explain that no-fault liability for medical error has proven far more popular with scholars than legislators. There are only a few pockets of strict liability in medical malpractice in the USA. Qualifying birth injury cases in Virginia and Florida are excluded from the tort system and are handled through an administrative system. Ironically, plaintiffs with strong cases prefer to litigate in the tort system because they can recover more, while plaintiffs with weak cases prefer the no-fault system. Products liability cases involving medical devices also qualify for strict liability treatment. ${ }^{46}$

No-fault compensation is not popular in Indonesia. Although some countries have adopted the scheme in medical injury cases for several decades, most people in Indonesia remain unfamiliar with it. The scheme is good in the sense that it may save the injured patients from the hurdle in proving medical errors. This may answer the issue of the patient's lack of access to relevant evidence. However, it seems too idealistic for the current situation in Indonesia when financial resources

\footnotetext{
${ }^{45}$ By not reporting this information to the NPDB, UMHS reduces an important barrier to doctor participation in this CRP. ibid.

${ }^{46}$ Hayman and Silver (n 12).[17].
} 
are still an issue. Similar to the USA, this scheme is good for academic discourse but inapplicable in practice.

\section{Conclusion}

Various innovations have been made in the USA that Indonesia can learn from, especially the pretrial screening process. A pretrial screening panel will settle the question of the merit of medical malpractice cases. Clarity on the merit of medical malpractice claims may reduce frivolous actions from patients and protect doctors from unnecessary legal action in Indonesia. A medical disciplinary tribunal can be used as a pretrial screening panel rather than establish a new institution to run the pretrial screening process.

\section{Bibliography}

Ali N, 'Facilitative Mediation in Resolving Medical Negligence Disputes' ( $^{\text {th }}$ APMF Conference, Kuala Lumpur, Malaysia, 16-18 June 2008).

Bal BS, 'An Introduction to Medical Malpractice in the United States' (2009) 467 Clinical Orthopaedics and Related Research.

Boulle L and Kelly KJ, Mediation: Principles, Process, and Practice (Butterworths 1998).

Boulle L and Nesic M, Mediation: Principles, Process, and Practice (Butterworths 2001).

Budetti PP and Winters TM, 'Medical Malpractice Law in United States' (The Henry J Kaiser Family Foundation 2005).

'Connecticut Mandates Mediation for Medical Malpractice Cases'.

Farrar J, Legal Reasoning (Thomson Reuters 2010).

Folberg J and Taylor A, Mediation: A Comprehensive Guide to Resolving Conflict without Litigation (Jossey-Bass Publishers 1984).

Fraser Jr JJ, 'Technical Report: Alternative Dispute Resolution in Medical Malpractice' (2001) 107 Pediatrics. 
Hayman DA and Silver C, 'Medical Malpractice and Global Perspective: How Does the USA Do It' (2012) 87 Chicago Kent Law Review.

Heath SW, Risk Management and Medical Liability (Indian Health Service 2006).

Hookman P, Medical Malpractice Expert Witnessing: Introductory Guide for Doctor and Medical Professionals (CRC Press 2008).

Kass JS and Rose RV, 'Medical Malpractice Reform: Historical Approaches, Alternative Models, and Communication and Resolution Programs' (2016) 18 American Medical Association Journal of Ethics.

Liebman CB, 'Medical Malpractice Mediation, Benefits Gained, Opportunities Lost' (2011) 74 Law and Contemporary Problem.

Liebman CB and Hyman CS, 'Disclosure and Fair Resolution of Adverse Events' in William M Sage and Roger Kersh (eds), Medical Malpractice and the USA Health Care System (CUP 2006).

McClellan FM, Medical Malpractice (Temple U Press 1994).

OALAdmin, 'How Is Medical Malpractice Different in the USA?' (Nelson MacNeil, Rayfield Trial Attorneys PC, 13 November 2017) <www.nelsonmacneil.com/ blog/how-medical-malpractice-different-us/>.

Rosengard LA and Parker M, 'Committing to Mediation: Enriched Resolution of Medical Malpractice Actions for Patients, Doctors and Insurance Companies' (2009).

Spencer D and Altobelli R, Dispute Resolution in Australia: Cases, Commentary and Materials (Lawbook Co 2005).

Spencer D and Brogan M, Mediation Law and Practice (CUP 2006).

van Velthoven BCJ and van Wijck PW, 'Medical Liability: Do Doctors Care?' (2012) 33 (2) Recht der Werkelijkheid 28.

United States Department of State, Bureau of International Information Programs, 'Outline of the USA Legal System' (2004).

Williams R, Should the State Provide ADR Services (CJQ 1987).

World Bank, 'Medical Malpractice Systems around the Globe: Examples from the USA- Tort Liability System and the Sweden- No Fault System' (2003). 
Yardley MJ, 'Malicious Prosecution: A Doctor's Need for Reassessment' (1984) 60 Chicago Kent Law Review.

Yee F, 'Mandatory Mediation: The Extra Dose Needed to Cure the Medical Malpractice Crisis' (2006) 7 Cardozo Journal of Conflict Resolution.

HOW TO CITE: Muh Endriyo Susila, 'Medical Malpractice in the United States of America: Lessons to Learn for Indonesia' (2021) 36 Yuridika. 